\title{
Aggression in drug-dependent in-patients
}

\section{AIMS AND METHOD}

Associations have been reported between aggression and psychoactive substance use, and a link with violence has been demonstrated in community samples. This study aimed to assess the prevalence and nature of aggressive incidents and to examine the factors associated with violence in a specialist substance misuse treatment unit. Data were collected about assaults, aggressive patients and the object of their aggression during a 12-month period.

\section{RESULTS}

Eighteen of 165 patients admitted during this period were involved in aggressive incidents. Patients dependent on more than one substance were significantly more aggressive than other categories of drug users. Past history of assaultive behaviour, younger age group and shorter duration of use were also significantly associated with incidents of aggression. Socio-demographic variables such as gender, marital and employment status were poor predictors of aggression.

\begin{abstract}
CONCLUSIONS
The incidence of serious violence in this substance misuse treatment unit was low when compared with other psychiatric units. The findings suggest that there are differences in levels of aggression among the various types of drug users. The study reinforces the need for an accurate drug history in order to improve the quality of risk assessment.
\end{abstract}

The ability to predict the likelihood of aggression is an important part of psychiatric practice, and an understanding of the factors that may increase the risk of assault is useful in clinical practice. Research conducted with in-patient samples has shown increased rates of violence associated with schizophrenia (Tardiff \& Sweillam, 1982; McNiel et al, 1988; Binder \& McNiel, 1995), organic mental disorders (Tardiff \& Sweillam, 1982; Hodgkinson et al, 1985), mania (McNiel et al, 1988; Binder \& McNiel, 1995), personality disorders and mental retardation (Tardiff \& Sweillam, 1982; Hodgkinson et al, 1985). Associations have been reported between in-patient aggression and psychoactive substance use (Blomhoff et al, 1990), and a link with violence has been demonstrated in community samples (Swanson et al, 1990; Tardiff et al, 1997). Dual diagnosis of a severe mental illness and a substance misuse disorder has a highly significant association with aggression (Scott et al, 1998). There is evidence that the type of drug used may be important, with stimulant drugs such as cocaine and amphetamine increasing the risk of violence (Miles et al, 2003).

Although there is a general agreement that substance misuse increases the risk of in-patient aggression, much of the research supporting this has been conducted in psychiatric hospitals and the results may not be generalisable to specialist substance misuse treatment units. To date there has been no study of the incidence of aggression in such units, and the characteristics of aggressive, drug-dependent patients are not clear. As a result, clinicians are forced to take important decisions about risk management in substance misuse in-patient settings without adequate knowledge of factors predicting the risk of aggression. In this study we aimed to determine the rates of aggression among drugdependent in-patients during their admission, and to describe the nature of violent episodes in terms of target and severity of injury. In doing so, we aimed to clarify the demographic and diagnostic categories of patients that present a greater risk of aggressive incidents.

\section{Method}

The Addictive Behaviours Centre is a 16-bedded inpatient unit providing a detoxification service for alcohol and other substances for Birmingham and neighbouring areas in the West Midlands. All patients are admitted voluntarily and enter into a treatment contract at the time of admission, one of the clauses of which defines acceptable behaviour on the unit. Patients are told that verbal or physical aggression, racist comments or possession of offensive weapons are prohibited, and that a written warning will be administered should such an episode take place. All such incidents result in the completion of an incident report form, and any repetition of the behaviour leads to premature discharge from the unit.

This study retrospectively reviewed all incident report forms completed between April 1999 and March 2000. Each form was analysed and information extracted according to a data collection pro forma. In addition, the clinical notes of all patients admitted during the study period were examined in order to identify any unreported incidents. For the purpose of our study, an 'incident' was defined as any act of physical or verbal aggression with a hostile intent by a patient towards a fellow patient, a member of staff or property. The severity of assault was rated on a six-point scale devised in a previous study (Miller et al, 1993):

- no injury (verbal threat only)

- no injury (property damage)

- unlikely injury (push or pull)

- minor injury (scratch or slap)

- moderate injury (punch, bite or kick)

- considerable injury (sustained assault) 
Table 1. The nature of aggressive incidents and the victims

original papers
Patients $(n=18)$

$n(\%)$

Incident

No injury (verbal threats only)

12 (67)

No injury (property damage)

2 (11)

Unlikely injury

Minor injury

Moderate injury

Considerable injury

Total

Aggression directed towards

Fellow patient

Nursing staff

Property

Total

Demographic data were also collected on all patients, as well as diagnostic information based on the ICD-10 classification system (World Health Organization, 1992). The characteristics of those involved in aggressive incidents were compared with those of others who had not been aggressive; all data analyses were performed using the Statistical Package for the Social Sciences, version 10.0. Statistical significance was established using the $\chi^{2}$ test for categorical data, with Fisher's exact test employed when appropriate, and the Mann-Whitney $U$ test for continuous data; a $P$ value of less than 0.05 was considered significant.

\section{Results}

Of the 165 patients admitted during the study period, most were male $(73 \%)$, under 50 years old $(89 \%)$, White $(83 \%)$ and unemployed (90\%). The most frequent substances of dependence were alcohol (54\%) and opiates (28\%), with multiple drug dependence (15\%) also prominent. Nearly a third (31\%) of people in the sample had an additional ICD-10 psychiatric diagnosis (with depression being the most common), and two-thirds had a forensic history (a history of contact with the judicial system for any criminal behaviour). A total of 18 patients were classified as having been aggressive during their inpatient stay. A majority of the incidents $(67 \%)$ were verbal threats only, and there was no serious incident during the study period. Physical aggression (i.e. contact assault) was rare, occurring in just $4 \%$ of all admissions. Staff and fellow patients were the victims in eight incidents each and property was damaged in two incidents (Table 1).

The aggressive patients were significantly younger than the non-aggressive group (mean age 42.7 years $v$. 37.8 years, $Z=-2.058, P=0.04)$ and had a shorter duration of substance use (14.1 years $v$. 19.8 years, $Z=-2.186$, $P=0.029$ ). Patients with polydrug dependency were significantly more aggressive than all the other patients combined $\left(\chi^{2}=9.63, P=0.006\right)$, and those dependent on alcohol were significantly less aggressive than all other groups $\left(\chi^{2}=5.566, P=0.018\right)$. There was no statistically significant difference between the aggressive and nonaggressive groups of patients in terms of gender, race, employment status and the presence or absence of

Table 2. Comparison of aggressive and non-aggressive patients

Cases with no record of aggression $(n=147) \quad$ Cases with a recorded episode of aggression $(n=18)$ $n(\%)$ $n(\%)$

Marital status

Divorced/separated

$42(29)$

$54(37)$

$5(28)$

Married

51 (35)

$4(22)$

Single

106 (72)

9 (50)

Male

Female

41 (28)

15 (83)

Ethnicity

White

124 (84)

3 (17)

Non-White

23 (16)

$13(72)$

Main diagnosis

Multiple drug dependence

17 (12)

$5(28)$

Opiate dependence

40 (27)

7 (39)

Alcohol dependence

$84(57)$

6 (33)

Other drug dependence

6 (4)

$5(28)$

Additional diagnosis

Present

46 (31)

$0 \quad(0)$

Absent

$101(69)$

6 (33)

Forensic history

Present

95 (65)

$12(67)$

Absent

52 (35)

$13(72)$

Past episode of violence

Present

$47(32)$

5 (28)

Absent

100 (68)

$10(56)$

8 (44) 
additional diagnosis (Table 2). A previous forensic history was not associated with aggression, although there was some evidence that a past history of violence either in the hospital or in the community was more common in the aggressive group ( $56 \%$ v. $32 \%, \chi^{2}=3.944, P=0.047$ ).

\section{Discussion}

In this study the prevalence of contact assaults (those involving more than verbal aggression) was $4 \%$, which is lower than the $7-10 \%$ found in studies in psychiatric units (Miller et al, 1993). This low rate may be explained by the fact that the sample contained a large proportion of patients who were motivated to change their behaviour, and none of the patients was detained under the Mental Health Act 1983. In addition, the clear clinical boundaries set by the treatment contract imposed on everyone admitted to the unit probably contributed to the lower level of assaults. Younger patients were more likely to be aggressive than older patients, a finding in agreement with results from other studies (Tardiff \& Sweillam, 1982; James et al, 1990). The statistical analysis did not suggest that comorbidity with other psychiatric disorders was associated with aggressive episodes, but it was noticeable that three out of four people with schizophrenia were involved in recorded incidents.

The study showed that people using more than one illegal drug were significantly more likely to be aggressive than others. Such patients undergo a complicated withdrawal process, and may experience a range of physical and psychological withdrawal symptoms. For example, the adrenergic discharge associated with opiate withdrawal may lead to irritability and thus to aggression. Four out of seven polydrug users who were involved in incidents of aggression during their admission were also dependent on cocaine, which in itself has been associated with aggressive behaviour (Tardiff et al, 1997). Other factors independent of the withdrawal process predispose this group to aggression. Some authors have suggested a complex inter-relationship between substance type, personality, life events and sociocultural factors (Fagan, 1990). People using more than one illegal drug tend to have a range of other medical and psychosocial problems (Schuckit, 2000), and this may in turn cause difficulties in their management. Our experience suggests that this group of patients is particularly challenging to manage, as it can be difficult to negotiate an appropriate rate and type of detoxification. There is a need for very clear treatment contracts before admission to prevent misconceptions regarding the purpose of admission.

Obvious limitations to our study are the retrospective nature of the data collection and the reliance on recorded incidents. The latter is likely to have led to an underestimate of the number of aggressive incidents, particularly those not involving physical aggression. The study numbers were small and the results may not be generalisable to other units. However, we feel that the results are helpful in suggesting risk factors for aggressive incidents in substance misuse in-patient treatment services. Professionals working in all in-patient psychiatric services should be aware of the need to assess risk carefully, and pay particular attention to groups such as younger patients with polydrug use who may need increased support in order to prevent such aggressive incidents.

\section{Acknowledgements}

We are grateful to Dr Syed Haque for his advice on statistics and to Mrs Anne Farmer, Mrs Elizabeth Cooksey and Mrs Joanne Williams for their help with collecting and organising data.

\section{References}

BINDER, R. L. \& McNIEL, D. E. (1995) Effects of diagnosis and context on dangerousness. American Journal of Psychiatry, 145, 728-732.

BLOMHOFF, S., SEIM, S. \& FRIIS, S. (1990) Can prediction of violence among psychiatric inpatients be improved? Hospital and Community Psychiatry, 41, 771-775.

FAGAN, J. (1990) Intoxication and aggression. In Drugs and Crime (eds M. Tonry \& J. Q. Wilson). Chicago: University of Chicago Press.

HODGKINSON, P. E., McIVOR, L. \& PHILLIPS, M. (1985) Patient assault on staff in a psychiatric hospital: a twoyear retrospective study. Medicine, Science and the Law, 25, 288-294.

JAMES, D. V., FINEBERG, N. A., SHAH, A. K., et al (1990) An increase in violence on an acute psychiatric ward. British Journal of Psychiatry, 158, 846-852.

McNIEL, D. E., BINDER, R. L. \& GREENFIELD,T. K. (1988) Predictors of violence in civilly committed acute psychiatric patients. American Journal of Psychiatry, 145, 965-970.

MILES, H., JOHNSON, S., AMPONSAHAFUWAPE, S., et al (2003)

Characteristics of subgroups of individuals with psychotic illness and a comorbid substance use disorder. Psychiatric Services, 54, 554-561.
MILLER, R. J., ZADOLINNYJ, K. \& HAFNER, R. J. (1993) Profiles and predictors of assaultiveness for different psychiatric ward populations. American Journal of Psychiatry, 150, 1368-1373.

SCHUCKIT, M. A. (2000) Drug and Alcohol Abuse: A Clinical Guide to Diagnosis and Treatment, pp. 278 290. NewYork: Kluwer.

SCOTT, H., JOHNSON, S., MENEZES, P., et al (1998) Substance misuse and risk of aggression and offending among the severely mentally ill. British Journal of Psychiatry, 172, 345-350.

SWANSON, J.W., HOLZER, C. E., GANJU,V. K., et al (1990) Violence and psychiatric disorders in the community: evidence from the Epidemiological Catchment Area surveys. Hospital and Community Psychiatry, 41, 761-770.

TARDIFF, K. \& SWEILLAM, A. (1982)

Assaultive behaviour among chronic inpatients. American Journal of Psychiatry, 139, 212-215.

TARDIFF, K., MARZUK, P. M., LEON,

A. C., et al (1997) Violence by patients admitted to a private psychiatric hospital. American Journal of Psychiatry, 154, 88-93.

WORLD HEALTH ORGANIZATION (1992) International Statistical Classification of Diseases and Related Health Problems (ICD-10). Geneva:WHO.

*G. S. Rajesh Specialist Registrar, Addictive Behaviours Centre, 120-122 Corporation Street, Birmingham B4 6SX ，Ed Day Senior Clinical Lecturer and Honorary Consultant in Addiction Psychiatry, Addictive Behaviours Centre, Birmingham

original papers 